\title{
Social support, adherence to Mediterranean diet and physical activity in adults: results from a community-based cross-sectional study
}

Elpiniki Laiou ${ }^{1,2}$, Iro Rapti ${ }^{1}$, Georgios Markozannes ${ }^{1}$, Luisella Cianferotti ${ }^{3}$, Lena Fleig ${ }^{4,5}$, Lisa Marie Warner ${ }^{4,5}$, Lourdes Ribas ${ }^{6}$, Joy Ngo $^{6}$, Sergio Salvatore ${ }^{7}$, Antonia Trichopoulou, Antonella Vigilanza ${ }^{7}$, Stavroula Tsiara ${ }^{1,2}$, Georgia Martimianaki ${ }^{8}$, Barbara Pampaloni ${ }^{9}$, Luis Serra Majem ${ }^{6,10,11}$, Ralf Schwarzer ${ }^{4,12}$, Maria Luisa Brandi ${ }^{3} \dagger$ and Evangelia E. Ntzani ${ }^{1,13,14 * \dagger}$ (1)

${ }^{1}$ Department of Hygiene and Epidemiology, University of Ioannina School of Medicine, Ioannina, Greece

${ }^{2}$ Department of Nursing, University of Ioannina, Ioannina, Greece

${ }^{3}$ Department of Surgery and Translational Medicine, University of Florence, Florence, Italy

${ }^{4}$ Department of Health Psychology, Freie Universität Berlin, Berlin, Germany

${ }^{5}$ MSB Medical School Berlin, Berlin, Germany

${ }^{6}$ Nutrition Research Foundation, Barcelona Science Park, Barcelona, Spain

${ }^{7}$ ISBEM, University of Salento, Lecce, Italy

${ }^{8}$ Hellenic Health Foundation, Athens, Greece

${ }^{9}$ Fondazione F.I.R.M.O., Florence, Italy

${ }^{10}$ University of Las Palmas de Gran Canaria, Research Institute of Biomedical and Health Sciences (IUIBS), Preventive Medicine Service, Centro Hospitalario Universitario Insular Materno Infantil (CHUIMI), Canarian Health Service, Las Palmas, Spain

${ }^{11}$ CIBER de la Fisiopatología de la Obesidad y Nutrición (CIBEROBN), Instituto de Salud Carlos III (ISCIII), Madrid, Spain

${ }^{12}$ Department of Clinical, Health and Rehabilitation Psychology, SWPS University of Social Sciences and Humanities, Wroclaw, Poland

${ }^{13}$ Center for Evidence Synthesis in Health, Department of Health Services, Policy and Practice, School of Public Health, Brown University, Providence,

RI, USA

${ }^{14}$ Institute of Biosciences, University Research Center of loannina, University of Ioannina, Ioannina, Greece

(Received 2 October 2020 - Accepted 8 October 2020)

Journal of Nutritional Science (2020), vol. 9, e53, page 1 of 9

doi:10.1017/jns.2020.46

Abstract

There is a growing recognition that social support can potentially exert consistent or opposing effects in influencing health behaviours. The present paper presents a cross-sectional study, including 2,064 adults from Italy, Spain and Greece, who were participants in a multi-centre randomised controlled trial (C4H study), aiming to examine whether social support is correlated with adherence to a healthy Mediterranean diet and physical activity. Social support data were available for 1,572 participants. The majority of the sample reported emotional support availability ( $84 \cdot 5 \%)$, financial support availability $(72 \cdot 6$ $\%)$ and having one or more close friends $(78 \cdot 2 \%)$. Mediterranean diet adherence was significantly associated with emotional support $(P=0 \cdot 009)$ and social network support $(P=0 \cdot 021)$. No statistically significant associations were found between participant physical activity and the social support aspects studied. In conclusion, emotional and social network support may be associated with increased adherence to the Mediterranean diet. However, further research is needed to evaluate the role of social support in adherence to healthy Mediterranean diet.

Key words: Social support: Mediterranean diet: Physical activity: Cross-sectional

* Corresponding author: Evangelia E. Ntzani, fax +3026510 07853, e-mail entzani@uoi.gr; entzani@gmail.com

†The authors Maria Luisa Brandi and Evangelia E. Ntzani contributed equally to this work.

(C) The Author(s), 2020. Published by Cambridge University Press on behalf of The Nutrition Society. This is an Open Access article, distributed under the terms of the Creative Commons Attribution licence (http://creativecommons.org/licenses/by/4.0/), which permits unrestricted re-use, distribution, and reproduction in any medium, provided the original work is properly cited. 


\section{Introduction}

Social support is defined as the perception that one is accepted, cared for, has assistance available from other people, and that one is part of a supportive social network. It has a complex, multi-level character that involves voluntary associations as well as formal (healthcare professionals and organisations) and informal (family members, friends and peers) relationships with others. Moreover, it is perceived differently on the basis of the recipient's gender, racial or ethnic background, or cultural practices ${ }^{(1-4)}$. Several behaviour change theories, such as the Social Cognitive Theory ${ }^{(5)}$, the Theory of Planned Behaviour ${ }^{(6)}$, the Social-Ecological Model $^{(7)}$ and the Health Action Process Approach ${ }^{(8)}$, draw attention to the importance of social support and social connectedness in achieving and maintaining behaviour change. There is a considerable amount of published research assessing the proposed associations between social support and aspects of physical and mental health such as dietary behaviours, physical activity, smoking, substance or alcohol use, chronic illness management, suicide or self-injury, cardiovascular disease (CVD) and cancer progression. However, in previous research, social support has not been deemed as a consistent predictor of dietary behaviours ${ }^{(9-11)}$, while it appeared to have a moderate effect on exercise behaviours by indirectly improving engagement, compliance and adherence to physical activity ${ }^{(12)}$. Moreover, whether social support is positively or negatively associated with health outcomes and health behaviours depends on the operationalisation of the construct. Perceived social support (prospective availability) and social network size usually show positive associations, while received social support (retrospective assessment of help received) is often found to relate negatively to health and health behaviours ${ }^{(13,14)}$.

Non-communicable diseases, including diabetes and obesity, are a major challenge for health and development. Based on the present evidence, regular physical activity and Mediterranean diet have been proven to help prevent and treat non-communicable diseases, including CVD, type 2 diabetes, some cancers and cognitive impairment ${ }^{(15-18)}$. It also helps to prevent hypertension, overweight and obesity and can improve mental health, quality of life and well-being ${ }^{(18)}$. Recently, there has been an overall aim of providing national and regional level policymakers with guidance on the frequency, duration, intensity, type and total amount of physical activity and the healthy diet needed for the prevention of noncommunicable diseases ${ }^{(19,20)}$.

In addition, online social networks have seen enormous growth in popularity in recent years, and yet, there are many uncertainties as to whether, and how, they might be harnessed to improve health behaviours also through the mediation of social support ${ }^{(21)}$. Due to the radical shift in society involving digital technology, the conclusions from the pre-digital era need to be re-evaluated. Focusing on aspects of social support such as emotional support, financial support and social network ties, the aim of the present study was to examine whether there is an association between social support and adherence to a healthy Mediterranean diet and physical activity.

\section{Methods}

\section{Study design and participants}

This cross-sectional study used baseline data from the CREDITS4HEALTH (C4H) study, a parallel-group, multicentre, randomised controlled community-based trial (RCT). The $\mathrm{C} 4 \mathrm{H}$ study aimed to assess the effects of an online platform that supports people in enhancing their level of physical activity and adopting a healthy Mediterranean diet by means of a person-centred approach, providing personalised plans and suggestions along with psychological and social support ${ }^{(22)}$.

Participants were adults, aged 18-65 years, in apparently good health, with the ability of regular internet access through technological devices (PC, tablet and smartphone), and residing in the Florence metropolitan area and the Salento region (Italy), Girona (Spain), and the Pylos Nestoras and Kalamata municipalities (Greece). Individuals with pregnancy, serious weight loss for unexplained reasons $(>5 \mathrm{~kg}$ in the previous 6 months), chronic disease or disability, presence of conditions with special diet needs and/or advised not to perform physical activity (e.g. end-stage renal disease), inability to use a computer and navigate the web and inability to adhere to the required study centre visits were excluded.

During a baseline visit at the research centres, each participant answered questions related to social background, chronic diseases and pharmacological treatments. Anthropometric measurements (weight, height, BMI, waist circumference and body composition) and blood pressure measurements were recorded by trained staff in accordance with the $\mathrm{C} 4 \mathrm{H}$ operations protocol. Participants were also invited to undergo blood testing at associated laboratories for the following parameters: total cholesterol, HDL, LDL, triglycerides, glucose, HbA1c and uric acid.

\section{Social support assessment}

Social support was evaluated using the social support questionnaire (SSQ) of the 2005 National Health and Nutrition Examination Survey (NHANES), a seven-item, selfadministered questionnaire assessing the perceived availability of social support and the individuals' level of satisfaction with the support provided and received. The questions were selected from the Yale Health and Aging Study (MacArthur Studies of Successful Aging) ${ }^{(23)}$ and the Social Network Index - Alameda County Study ${ }^{(24)}$. It includes questions considering the availability of emotional support, the people providing emotional support (friends, spouse, children, co-workers, neighbours and other) as well as the level of received and desired emotional support ${ }^{(25)}$ (Table 2). It should be noted that currently, there is no perfect measure of social support, especially given that the lack of consensus regarding the definition and conceptualisation of social support, as well as the relative gap of strong psychometric evidence in the literature for many of the currently available measures. The SSQ is easily accessible via the Internet, scoring is simple and the questionnaire is quite short, limiting the amount of time consumed to be filled in. Furthermore, the seven included questions are simply formed with comprehensive 
probes and examples to promote the level of understanding. A very important aspect of the SSQ is the inclusion of questions evaluating social support provided by religious services (e.g. church) and tangible support (financial assistance, material goods or services).

\section{Physical activity and Mediterranean diet adherence assessment}

Physical activity levels were assessed using the General Practice Physical Activity Questionnaire (GPPAQ), a seven-item screening tool developed by the London School of Hygiene \& Tropical Medicine as a validated short measure of physical activity used to assess adult (16-74 years) physical activity levels. It includes questions about the type and amount of physical activity involved in one's occupation, hours spent on physical exercise, cycling, walking, housework/childcare and gardening/DIY, providing a four-level categorisation of respondents as active, moderately active, moderately inactive and inactive ${ }^{(26)}$. Considering psychometric properties of the GPPAQ, for reliability, $56 \%(70 / 126)$ and $67 \%(87 / 129)$ of controls scored the same at 3 and 12 months, respectively, as they scored at baseline. GPPAQ had $19 \%(13 / 69)$ sensitivity and $85 \%(186 / 220)$ specificity ${ }^{(27)}$.

Adherence to the Mediterranean dietary pattern was evaluated using the Mediterranean Diet Adherence Screener (MEDAS), adapted from a previously validated 14-item index ${ }^{(28)}$ with higher scores indicating a healthier diet. MEDAS is a brief 14-item questionnaire which is less timedemanding, less expensive and requires less collaboration from participants than the usual full-length questionnaires or other more comprehensive methods. In addition, it provides the unique window of opportunity to provide feedback to the participant immediately after the questionnaire is completed $^{(29,30)}$. The MEDAS score correlated significantly with the corresponding FFQ PREDIMED score ( $r$ 0.52; intraclass correlation coefficient 0.51 ) and in the anticipated directions with the dietary intake reported on the $\mathrm{FFQ}^{(27)}$.

To facilitate data analyses, the number of close friends was re-coded into four categories to identify distinct sizes of network: $0 ; 1-4 ; 5-9$ and 10 or more close friends, and church attendance was re-coded as never, occasionally, weekly and more than weekly, categorisations previously used by McKenzie et al. ${ }^{(31)}$. Body mass index (BMI) was re-coded to underweight, normal, overweight and obese based on the WHO classification ${ }^{(32)}$.

\section{Statistical analysis}

Descriptive statistics were calculated to investigate sample characteristics and the distribution of the studied variables. In order to provide more detailed information, baseline characteristics are presented according to recruiting centre as means $\pm \mathrm{SD}$, median (IQR) for non-normally distributed data and number (\%), using Pearson's $\chi^{2}$ tests, Fisher's exact tests and Kruskal-Wallis rank tests, as appropriate. The distribution of data was determined using the Shapiro-Wilks test of normality ${ }^{(32)}$. Mixed-effects models were applied to correlate physical activity and Mediterranean diet adherence from the social support variables and calculate effect estimates (Odds ratios (ORs) and $\beta$ ). Research centre area was used as a random-effect variable to account for differences across the four research centres. For each area, multiple ordinal and linear regression analyses were conducted to predict physical activity and Mediterranean diet adherence correspondingly from the social support variables. Age and sex were included as covariates in all the models. Complete cases analysis was used with regards to missing data. Differences were considered statistically significant if the $P$-value was $<0 \cdot 05$. The present study represents a cross-sectional assessment of the baseline data of the main study; thus, a power analysis was not pertinent. All analyses were performed using Stata (version 13.1; StataCorp, College Station, TX, USA).

Prior to the commencement of the study, ethical approval was obtained by the corresponding competent legal local Ethics Committees of each country and signed informed consent was obtained from all the participants. All the data were collected in compliance with the Declaration of Helsinki.

\section{Results}

Of the 2,064 subjects (361 from Florence, 372 from Salento, 713 from Girona and 618 from Kalamata) recruited from October 2015 to January 2016, social support data were available for 1,572 participants that were included in the present study. Table 1 shows the characteristics of the population under study. The average age was $40.9 \pm 11.5$ years and 952 $(60.6 \%)$ women were included. More than one-third (35.4 $\%)$ of the participants had university level education, while $31 \%$ had high school level education. Approximately $42 \%$ of the participants were married or cohabiting, while $32.2 \%$ were single or divorced. The majority of the participants $(80.2 \%)$ reported that they were non-smokers and approximately half $(52.5 \%)$ reported no alcohol consumption.

At the centre level, the population under study showed statistically significant differences for participant age, marital status, level of education, alcohol consumption, BMI, type 2 diabetes status, number of long-term medications used, physical activity and Mediterranean diet adherence (Table 1). There were no statistically significant differences between study centres with regards to participant sex, country of birth, smoking status, weight and hypertension status. More specifically, the 337 participants from Florence, Italy, had an average age of $45(38-52)$ years and $204(60.5 \%)$ were women. The vast majority of the participants $(94.1 \%)$ had a high school or university education. Approximately $57 \%$ of the participants were married or cohabiting, while $42 \%$ were single or divorced. The majority of the participants $(81.3 \%)$ reported that they were non-smokers and approximately half $(56 \cdot 4 \%)$ reported alcohol consumption. Most of the participants were active or moderately active $(65.2 \%)$ with a median MEDAS score of 8 (6-9). Prevalence of type 2 diabetes and hypertension was low $(0.6 \%$ and $10.1 \%$, respectively). Similar were the results for the participants from Salento, Italy (n 319) regarding the average age of 44 (36-52) years, female gender $(56.5 \%)$, marital and educational status. Most of the 
Table 1. Baseline characteristics of the included $\mathrm{C} 4 \mathrm{H}$ study participants

\begin{tabular}{|c|c|c|c|c|c|c|}
\hline & Florence ( $n$ 337) & Salento ( $n$ 319) & Girona ( $n$ 629) & $\begin{array}{l}\text { Pylos-Kalamata } \\
\qquad(n \text { 287) }\end{array}$ & Total $(N 1572)$ & $P$-value ${ }^{*}$ \\
\hline Age (years) & $45(38-52)$ & $44(36-52)$ & $40(32-48)$ & $36(23-47)$ & $42(32-50)$ & $<0.001$ \\
\hline Men, $n(\%)$ & $133(39.5)$ & $142(44.5)$ & $240(38 \cdot 2)$ & $105(36 \cdot 6)$ & $620(39.4)$ & 0.183 \\
\hline Marital status, $n(\%)$ & & & & & & $<0.001$ \\
\hline Single or divorced & $141(41 \cdot 8)$ & $119(37 \cdot 3)$ & $131(20 \cdot 8)$ & $115(40 \cdot 1)$ & $506(32 \cdot 2)$ & \\
\hline Married or cohabiting & $191(56 \cdot 7)$ & $195(61 \cdot 1)$ & $219(34 \cdot 8)$ & $47(16.4)$ & $652(41.5)$ & \\
\hline Widow/Widower & $4(1 \cdot 2)$ & $5(1 \cdot 6)$ & $4(0 \cdot 6)$ & $1(0 \cdot 3)$ & $14(0 \cdot 9)$ & \\
\hline Missing & $1(0.3)$ & $0(0.0)$ & $275(43.7)$ & $124(43 \cdot 2)$ & $400(25.4)$ & \\
\hline Born in study country, $n(\%)$ & & & & & & 0.184 \\
\hline Yes & $311(92 \cdot 3)$ & $306(95 \cdot 9)$ & $321(51 \cdot 0)$ & $149(51.9)$ & $1087(69 \cdot 1)$ & \\
\hline No & $25(7.4)$ & $13(4 \cdot 1)$ & $24(3 \cdot 8)$ & $14(4 \cdot 9)$ & $76(4.8)$ & \\
\hline Missing & $1(0 \cdot 3)$ & $0(0.0)$ & $284(45 \cdot 2)$ & $124(43 \cdot 2)$ & $409(26 \cdot 0)$ & \\
\hline Education level, $n(\%)$ & & & & & & $<0.001$ \\
\hline University & $173(51 \cdot 3)$ & $120(37 \cdot 6)$ & $197(31 \cdot 3)$ & $66(23.0)$ & $556(35.4)$ & \\
\hline High school & $144(42 \cdot 7)$ & $141(44 \cdot 2)$ & $106(16 \cdot 9)$ & $97(33.8)$ & $488(31.0)$ & \\
\hline Primary/Middle school & $18(5 \cdot 3)$ & $58(18 \cdot 2)$ & $48(7 \cdot 6)$ & $0(0.0)$ & $124(7 \cdot 9)$ & \\
\hline Missing & $2(0 \cdot 6)$ & $0(0.0)$ & $278(33.2)$ & $124(43 \cdot 2)$ & $404(25 \cdot 7)$ & \\
\hline \multicolumn{7}{|l|}{ Smoking, $n(\%)$} \\
\hline Yes & $63(18 \cdot 7)$ & $76(23 \cdot 8)$ & $112(17 \cdot 8)$ & $60(20 \cdot 9)$ & $311(19 \cdot 8)$ & 0.150 \\
\hline No & $274(81 \cdot 3)$ & $243(76 \cdot 2)$ & $517(82 \cdot 2)$ & $227(79 \cdot 1)$ & $1261(80 \cdot 2)$ & \\
\hline \multicolumn{7}{|l|}{ Alcohol, $n(\%)$} \\
\hline Yes & $190(56 \cdot 4)$ & $58(18.2)$ & $476(75 \cdot 7)$ & $22(7 \cdot 7)$ & $746(47.5)$ & $<0.001$ \\
\hline No & $147(43 \cdot 6)$ & $261(81.8)$ & $153(24 \cdot 3)$ & $275(92 \cdot 3)$ & $826(52.5)$ & \\
\hline BMI $\left(\mathrm{kg} / \mathrm{m}^{2}\right)$ & $24.2(21.9-27.5)$ & $26.4(23.5-29.4)$ & $24.6(22 \cdot 2-27 \cdot 9)$ & $26.1(22.5-29 \cdot 2)$ & $25.1(22.5-28.5)$ & $<0.001$ \\
\hline \multicolumn{7}{|l|}{ Type 2 diabetes, $n(\%)$} \\
\hline Yes & $2(0 \cdot 6)$ & $0(0.0)$ & $6(1 \cdot 0)$ & $11(3 \cdot 8)$ & $19(1 \cdot 2)$ & $<0.001$ \\
\hline No & $335(99.4)$ & $319(100 \cdot 0)$ & $623(99 \cdot 0)$ & $276(96 \cdot 2)$ & $1553(98 \cdot 8)$ & \\
\hline \multicolumn{7}{|l|}{ Hypertension, $n(\%)$} \\
\hline Yes & $34(10 \cdot 1)$ & $36(11 \cdot 3)$ & $59(9.4)$ & $18(6 \cdot 3)$ & $147(9.4)$ & 0.184 \\
\hline No & $303(89.1)$ & $283(88.7)$ & $570(90 \cdot 6)$ & $269(93.7)$ & $1425(90 \cdot 6)$ & \\
\hline Number of long-term medications used ${ }^{a}$ & $0(0-1)$ & $1(1-1)$ & $0(0-1)$ & $0(0-1)$ & $0(0-1)^{\mathrm{a}}$ & $<0.001$ \\
\hline Antihypertensive, $n(\%)$ & $24(7 \cdot 1)$ & $32(10.0)$ & $30(4.8)$ & $13(4.5)$ & $99(6 \cdot 3)$ & 0.008 \\
\hline Hypolipidemic, $n(\%)$ & $8(2.4)$ & $6(1.9)$ & $21(3 \cdot 3)$ & $8(2 \cdot 8)$ & $43(2 \cdot 7)$ & 0.593 \\
\hline Physical activity, $n$ (\%) & & & & & & $<0.001$ \\
\hline Active & $139(41 \cdot 2)$ & $111(34 \cdot 8)$ & $334(53 \cdot 1)$ & $114(39 \cdot 7)$ & $698(44.4)$ & \\
\hline Moderately active & $81(24 \cdot 0)$ & $64(20 \cdot 1)$ & $130(20 \cdot 7)$ & $48(16 \cdot 7)$ & $323(20 \cdot 6)$ & \\
\hline Moderately inactive & $40(11.9)$ & $62(19.4)$ & $59(9.4)$ & $55(19 \cdot 2)$ & $216(13.7)$ & \\
\hline Inactive & $77(22 \cdot 8)$ & $82(25 \cdot 7)$ & $106(16 \cdot 8)$ & $70(24.4)$ & $335(21 \cdot 3)$ & \\
\hline MEDAS score & $8(6-9)$ & $7(6-9)$ & $8(6-9)$ & $6(5-8)$ & $7(6-9)$ & $<0.001$ \\
\hline
\end{tabular}

Data are presented as median (IQR) unless otherwise indicated.

Hypolipidemic medications included statins and fibrates.

BMI, Body mass index.

${ }^{\text {a }}$ Long-term medication use $N 1,022$, MEDAS score $N 1,569$.

* $P$-value for global comparisons between study areas, evaluated on the non-missing data. Pearson's $\chi^{2}$ test and Fisher's exact test for categorical variables and Kruskal-Wallis rank test for continuous variables.

participants were non-smokers $(76 \cdot 2 \%)$ and non-alcohol users $(81.8 \%)$. Almost half of the participants were moderately active or active $(54.9 \%)$ with a median MEDAS score of 7 (6-9). Only $36(11 \cdot 3 \%)$ participants reported hypertension and none was diabetic. Girona, Spain, contributed the largest number of participants ( $n$ 629). The average age was $40(32-$ $48)$ years with a predominance of female gender $(64 \cdot 8 \%)$. Regarding marital status, $34.8 \%$ of the participants were married or cohabiting, $20.8 \%$ were single or divorced, while 43.7 $\%$ of the information was missing. Almost half of the participants reported a high school or university education. The majority did not smoke $(82.2 \%)$ and consumed alcohol $(75.7 \%)$. Overall, $464(73.8 \%)$ participants were moderately active or active, with median MEDAS score of 8 (6-9). Prevalence of type 2 diabetes and hypertension was low (1\% and $9.4 \%$, respectively). Lastly, 287 participants came from Pylos-Kalamata, Greece, with a comparatively younger average age of 36 (23-47) and a female gender predominance $(63.4 \%)$. In contrast to the other countries, a lower percentage of participants $(16.4 \%)$ were married or cohabiting, $40.1 \%$ were single or divorced, while an accountable percentage of information $(43.2 \%)$ was missing. Educational level was in accordance with the other centres. The majority neither smoked $(79.1 \%)$ nor consumed alcohol $(92.3 \%)$. Overall, almost half of the participants $(56.4 \%)$ were moderately active or active, with the lowest median MEDAS score of 6 (5-8) compared to the rest of the three centres. Prevalence of type 2 diabetes and hypertension was $3.8 \%$ and $6.3 \%$, respectively.

The baseline social support characteristics of the $\mathrm{C} 4 \mathrm{H}$ participants are presented in Table 2 . The majority of the sample reported emotional support availability $(84.5 \%)$ or no need for it $(4.4 \%), 72.6 \%$ reported financial support availability and $78.2 \%$ reported having one or more close friends. Conversely, $59.4 \%$ reported never attending religious services. 
Table 2. Social support characteristics of the $\mathrm{C} 4 \mathrm{H}$ study participants

\begin{tabular}{|c|c|c|c|c|c|c|}
\hline & Florence & Salento & Girona & Pylos-Kalamata & Total & $P$-value* \\
\hline Emotional support availability, $n(\%)$ & $n 337$ & $n 319$ & $n 629$ & $n 287$ & $N 1,572$ & 0.001 \\
\hline Yes & $275(81.6)$ & $265(83 \cdot 1)$ & $555(88.2)$ & $233(81 \cdot 2)$ & $1328(84.5)$ & \\
\hline No & $29(8.6)$ & $22(6 \cdot 9)$ & $33(5 \cdot 2)$ & $15(5 \cdot 2)$ & $99(6 \cdot 3)$ & \\
\hline Do not need help & $8(2 \cdot 4)$ & $17(5 \cdot 3)$ & $23(3.7)$ & $21(7 \cdot 32)$ & $69(4.4)$ & \\
\hline Refused/Do not know & $25(7.4)$ & $15(4 \cdot 7)$ & $18(2 \cdot 9)$ & $18(6 \cdot 3)$ & $76(4 \cdot 8)$ & \\
\hline More emotional support needed during last 12 months, $n(\%)$ & $n 336$ & $n 318$ & $n 628$ & $n 285$ & $N 1,567$ & $<0.001$ \\
\hline Yes & $107(31.9)$ & $94(29 \cdot 6)$ & $192(30 \cdot 6)$ & $97(34.0)$ & $490(31 \cdot 3)$ & \\
\hline No & $133(39 \cdot 6)$ & $150(47 \cdot 2)$ & $271(43 \cdot 2)$ & $150(52 \cdot 6)$ & $704(44.9)$ & \\
\hline Refused/Do not know & $96(28.6)$ & $74(23 \cdot 3)$ & $165(26 \cdot 3)$ & $38(13 \cdot 3)$ & $373(23.8)$ & \\
\hline Emotional support needed, $n(\%)$ & $n 336$ & $n 318$ & $n 627$ & $n 285$ & $N 1,566$ & 0.029 \\
\hline A lot more & $24(7 \cdot 1)$ & $23(7 \cdot 2)$ & $45(7 \cdot 2)$ & $21(7.4)$ & $113(7 \cdot 2)$ & \\
\hline Some more & $46(13.7)$ & $40(12 \cdot 6)$ & 102(16.3) & $26(9 \cdot 1)$ & $214(13.7)$ & \\
\hline A little more & $101(30 \cdot 1)$ & $93(29 \cdot 3)$ & $192(30 \cdot 6)$ & $116(40 \cdot 7)$ & $502(32 \cdot 1)$ & \\
\hline Refused/Do not know & $165(49 \cdot 1)$ & $162(50 \cdot 9)$ & $288(45 \cdot 9)$ & $122(42 \cdot 8)$ & $737(47 \cdot 1)$ & \\
\hline Religious services attendance, $n(\%)$ & n 337 & n 319 & $n 629$ & $n 287$ & $N 1,572$ & $<0.001$ \\
\hline Never & $189(56 \cdot 1)$ & $101(31 \cdot 7)$ & $537(85.4)$ & $107(37 \cdot 3)$ & $934(59.4)$ & \\
\hline Occasionally & $97(28 \cdot 8)$ & $126(39.5)$ & $55(8 \cdot 7)$ & $142(49 \cdot 5)$ & $420(26 \cdot 7)$ & \\
\hline Weekly & $23(6 \cdot 8)$ & $51(16 \cdot 0)$ & $9(1.4)$ & $13(4.5)$ & $96(6 \cdot 1)$ & \\
\hline More than weekly & $7(2 \cdot 1)$ & $29(9 \cdot 1)$ & $3(0.5)$ & $7(2 \cdot 4)$ & $46(2 \cdot 9)$ & \\
\hline Refused/Do not know & $21(6 \cdot 2)$ & $12(3 \cdot 8)$ & $25(4 \cdot 0)$ & $18(6 \cdot 3)$ & $76(4 \cdot 8)$ & \\
\hline \multirow[t]{2}{*}{ Religious services attendance per year, median (IQR) } & $n 312$ & $n 304$ & $n 590$ & $n 268$ & $N 1,474$ & $<0.001$ \\
\hline & $0(0-5)$ & $7.5(0-52)$ & $0(0-0)$ & $4(0-10)$ & $0(0-6)$ & \\
\hline Financial help availability, $n(\%)$ & $n 336$ & $n 318$ & $n 627$ & $n 284$ & N 1565 & $<0.001$ \\
\hline Yes & $236(70 \cdot 2)$ & $215(67 \cdot 6)$ & $497(79 \cdot 3)$ & $188(66 \cdot 2)$ & $1,136(72 \cdot 6)$ & \\
\hline No & $34(10 \cdot 1)$ & $40(12 \cdot 6)$ & $56(8.9)$ & $41(14.4)$ & $171(10 \cdot 9)$ & \\
\hline Offered but declined & $16(4 \cdot 8)$ & $17(5 \cdot 4)$ & $16(2 \cdot 6)$ & $7(2.5)$ & $56(3.6)$ & \\
\hline Refused/Do not know & $50(14.9)$ & $46(14.5)$ & $58(9 \cdot 3)$ & $48(16 \cdot 9)$ & $202(12 \cdot 9)$ & \\
\hline Number of close friends, $n(\%)$ & $n 336$ & $n 319$ & $n 626$ & $n 286$ & $N 1,567$ & 0.120 \\
\hline 0 & $34(10 \cdot 1)$ & $35(11.0)$ & $67(10 \cdot 7)$ & $34(11.9)$ & $170(10 \cdot 8)$ & \\
\hline $1-4$ & $156(46 \cdot 4)$ & $145(45 \cdot 4)$ & $320(51 \cdot 1)$ & $143(50)$ & $764(48 \cdot 8)$ & \\
\hline $5-9$ & $83(24 \cdot 7)$ & $81(25.4)$ & $154(24 \cdot 6)$ & $64(22 \cdot 4)$ & $382(24.4)$ & \\
\hline $10+$ & $27(8 \cdot 0)$ & $20(6 \cdot 3)$ & $25(4 \cdot 0)$ & $7(2 \cdot 4)$ & $79(5 \cdot 0)$ & \\
\hline Refused/Do not know & $36(10 \cdot 7)$ & $38(11.9)$ & $60(9 \cdot 6)$ & $38(13.3)$ & $172(11 \cdot 0)$ & \\
\hline \multirow[t]{2}{*}{ Number of close friends, median (IQR) } & $N 300$ & $N 281$ & $N 566$ & $N 248$ & $N 1,395$ & 0.071 \\
\hline & $3(2-5)$ & $3(2-5)$ & $3(2-5)$ & $3(2-5)$ & $3(2-5)$ & \\
\hline
\end{tabular}

${ }^{*} P$-value for global comparisons between study areas, evaluated on the non-missing data. Pearson's $\chi^{2}$ test for categorical variables and Kruskal-Wallis rank test for continuous variables.

Statistically significant differences were found between the research centre areas pertaining to emotional support, financial support and religious services attendance, while there were no statistically significant differences pertaining to the participant number of close friends.

The results of the mixed effect models analyses are presented in Table 3 (physical activity) and Table 4 (Mediterranean diet adherence). Mediterranean diet adherence was significantly associated with emotional support availability $(P=0.009)$ and social network support in terms of the number of close friends $(P=0 \cdot 021)$, while there were no statistically significant differences found with regards to emotional support needs, financial support availability and religious services attendance. No statistically significant associations were found between participant physical activity (categorised in four levels) and any of the social support aspects studied. The unadjusted results of the mixed effect models (Supplementary Tables S1 and S2) and the results of the multivariate analyses for each research area (Supplementary Tables S3-S10) are included in the Supplementary material.

No statistically significant differences were found between the participants with available social support data and the participants with no available social support data in terms of sex and BMI, while the group of the participants with missing social support data was statistically significantly younger $(35 \cdot 1 \pm 13 \cdot 6$ years $v \cdot 40 \cdot 9 \pm 11 \cdot 5$ years; $P<0 \cdot 001)$.

\section{Discussion}

Our work assessed the correlation of social support parameters with adherence to a healthy Mediterranean diet and physical activity in 1,572 healthy participants from three Mediterranean countries. Mediterranean diet adherence was significantly associated with emotional support availability and social network support. That is, participants who did not report a lack of emotional support and those who reported a higher number of friends achieved higher Mediterranean adherence scores. In contrast, no statistically significant associations were found between Mediterranean diet adherence and emotional support need, religious service attendance and financial support. On the other hand, none of the social support aspects (emotional social support, financial support availability, social network availability and religious service attendance) were statistically significantly associated with physical activity level. 
Table 3. Baseline associations between social support and physical activity (GPPAQ)

\begin{tabular}{|c|c|c|c|c|c|c|}
\hline Question & Answer & Summary $\mathrm{OR}^{\mathrm{a}}$ & $95 \% \mathrm{Cl}$ & $P$-value & $N$ & Overall $P$-value \\
\hline \multirow{3}{*}{$\begin{array}{l}\text { Can you count on anyone to provide you with emotional } \\
\text { support such as talking over problems or helping you make a } \\
\text { difficult decision? }\end{array}$} & $\mathrm{No}^{\mathrm{b}}$ & 1 & & & 1,496 & 0.252 \\
\hline & Yes & 0.93 & $0.63-1.37$ & 0.713 & & \\
\hline & I do not need help & 1.41 & $0.76-2.60$ & 0.276 & & \\
\hline \multirow{2}{*}{$\begin{array}{l}\text { In the last } 12 \text { months, could you have used more emotional } \\
\text { support than you received? }\end{array}$} & Yes $^{\mathrm{b}}$ & 1 & & & 1,194 & 0.812 \\
\hline & No & 1.03 & $0.83-1.27$ & 0.812 & & \\
\hline \multirow[t]{3}{*}{ Emotional support: Would you say that you could have used... } & A lot more ${ }^{b}$ & 1 & & & 829 & 0.100 \\
\hline & Some & 1.36 & $0.89-2.07$ & 0.159 & & \\
\hline & A little more & 1.51 & $1 \cdot 03-2 \cdot 21$ & 0.033 & & \\
\hline \multirow[t]{2}{*}{ How often do you attend church or religious services? } & Never ${ }^{b}$ & 1 & & & 1,489 & 0.609 \\
\hline & Some & 0.94 & $0.75-1.18$ & 0.609 & & \\
\hline \multirow[t]{4}{*}{ How often do you attend church or religious services? } & Never ${ }^{\mathrm{b}}$ & 1 & & & 1,496 & 0.274 \\
\hline & Occasionally & 1.01 & $0.79-1.28$ & 0.951 & & \\
\hline & Weekly & 0.77 & $0.52-1.15$ & 0.198 & & \\
\hline & More than weekly & 0.65 & $0.37-1.14$ & 0.135 & & \\
\hline \multirow{3}{*}{$\begin{array}{l}\text { If you need some extra help financially, could you count on } \\
\text { anyone to help you? }\end{array}$} & $\mathrm{No}^{\mathrm{b}}$ & 1 & & & 1,363 & 0.239 \\
\hline & Yes & 0.77 & $0.56-1.05$ & 0.096 & & \\
\hline & Would not accept it & 0.73 & $0.41-1.29$ & 0.282 & & \\
\hline \multirow[t]{4}{*}{ In general, how many close friends do you have? } & $0^{\mathrm{b}}$ & 1 & & & 1,395 & 0.772 \\
\hline & $1-4$ & $1 \cdot 12$ & $0.82-1.52$ & 0.470 & & \\
\hline & $5-9$ & $1 \cdot 12$ & $0.80-1.57$ & 0.515 & & \\
\hline & $10+$ & 1.30 & $0.79-2.15$ & 0.303 & & \\
\hline
\end{tabular}

${ }^{a}$ OR provided from the performed ordinal regression and adjusted for age and sex with area specified as a random factor (i.e. random intercept models).

${ }^{\mathrm{b}}$ Reference category.

\section{Comparison to previous studies}

With regards to the available research on the relationship between social support and physical activity, the available evidence is limited in size and in methodological rigour mainly comprised of cross-sectional studies ${ }^{(33,34)}$. Overall, the evidence on adults is inconclusive ranging from positive associations in earlier studies ${ }^{(35)}$ to no or unclear evidence ${ }^{(34,36-39)}$.
Most studies adopted a cross-sectional design, they involved mainly healthy participants, they focused on the social support provided by friends and family, while a combination of selfreported and objectively measured level of physical activity was used to assess physical activity. Interestingly, provision of social support has been related to small, but significant associations with physical activity in children and adolescents ${ }^{(34,40)}$; cross-sectional and longitudinal studies have shown that social

Table 4. Baseline associations between social support and Mediterranean diet adherence (MEDAS)

\begin{tabular}{|c|c|c|c|c|c|c|}
\hline Question & Answer & $\beta^{\mathrm{a}}$ & $95 \% \mathrm{Cl}$ & $P$-value & $N$ & Overall $P$-value \\
\hline \multirow{3}{*}{$\begin{array}{l}\text { Can you count on anyone to provide you with emotional } \\
\text { support such as talking over problems or helping you make a } \\
\text { difficult decision? }\end{array}$} & $\mathrm{No}^{\mathrm{b}}$ & 0 & & & 1,493 & 0.009 \\
\hline & Yes & 0.67 & $0.21-1 \cdot 12$ & 0.004 & & \\
\hline & I do not need help & 0.90 & $0.21-1.58$ & 0.010 & & \\
\hline \multirow{2}{*}{$\begin{array}{l}\text { In the last } 12 \text { months, could you have used more emotional } \\
\text { support than you received? }\end{array}$} & Yes $^{\mathrm{b}}$ & 0 & & & 1,191 & 0.655 \\
\hline & No & 0.06 & -0.20 to 0.32 & 0.655 & & \\
\hline \multirow[t]{3}{*}{ Emotional support: Would you say that you could have used. . } & A lot more ${ }^{b}$ & 0 & & & 826 & 0.590 \\
\hline & Some & 0.17 & -0.35 to 0.69 & 0.523 & & \\
\hline & A little more & -0.02 & -0.49 to 0.44 & 0.930 & & \\
\hline \multirow[t]{2}{*}{ How often do you attend church or religious services? } & Never ${ }^{\mathrm{b}}$ & 0 & & & 1,486 & 0.104 \\
\hline & Some & -0.22 & -0.49 to 0.5 & 0.104 & & \\
\hline \multirow[t]{4}{*}{ How often do you attend church or religious services? } & Never ${ }^{b}$ & 0 & & & 1,493 & 0.404 \\
\hline & Occasionally & -0.23 & -0.51 to 0.06 & 0.119 & & \\
\hline & Weekly & -0.26 & -0.75 to 0.23 & 0.306 & & \\
\hline & More than weekly & -0.23 & -0.92 to 0.46 & 0.509 & & \\
\hline \multirow{3}{*}{$\begin{array}{l}\text { If you need some extra help financially, could you count on } \\
\text { anyone to help you? }\end{array}$} & $\mathrm{No}^{\mathrm{b}}$ & 0 & & & 1,360 & 0.930 \\
\hline & Yes & 0.05 & -0.31 to 0.42 & 0.778 & & \\
\hline & Would not accept it & 0.13 & -0.56 to 0.81 & 0.719 & & \\
\hline \multirow[t]{4}{*}{ In general, how many close friends do you have? } & $0^{\mathrm{b}}$ & 0 & & & 1,392 & 0.021 \\
\hline & $1-4$ & 0.26 & -0.11 to 0.63 & 0.169 & & \\
\hline & $5-9$ & 0.46 & $0.06-0.86$ & 0.024 & & \\
\hline & $10+$ & 0.82 & $0.23-1.41$ & 0.006 & & \\
\hline
\end{tabular}

\footnotetext{
${ }^{\text {a }}$ Adjusted for age and sex with area specified as a random factor (i.e. random intercept models).

${ }^{\mathrm{b}}$ Reference category.
} 
support provided by parents, father, mother, friends and relatives is positively and consistently related to higher physical activity levels in adolescents ${ }^{(40)}$. Given that self-efficacy and competence mediate the relationship between social support and physical activity, it is possible that social support indirectly influences physical activity levels through self-efficacy and other possible mediating constructs (e.g. enjoyment). Moreover, it is likely that the ways in which parents and friends provide social support and influence activity levels are different. For example, friends might contribute to positive experiences in physical education or organised physical activities, while parents could create a foundation for lifelong habits in physical activity in their children at an early age and provide support for their ongoing participation in physical activity during adolescence. Further research might investigate these possible mechanisms in more detail ${ }^{(40)}$.

Similarly to our study which significantly associated Mediterranean diet adherence to emotional support availability and social network support, previous research on the associations between social support and diet showed that the inclusion of planning for social support/social change has been associated with enhanced effectiveness of dietary interventions, resulting in increases in fruit and vegetable intakes ${ }^{(9-}$ 11,41-43). Nevertheless, there is a lack of evidence considering the Mediterranean diet exclusively. Socialisation in the form of sitting around the table and sharing food in company of family and friends (conviviality), a form of social support, is considered an inherent aspect of Mediterranean diet lifestyle $^{(44)}$. Yet, the role of the Mediterranean diet as a holistic lifestyle pattern, and not exclusively as a healthier diet, needs further evaluation. Perhaps the relationship to health may exist for the overall Mediterranean diet as a healthy lifestyle pattern, and not necessarily for an isolated aspect of its components.

\section{Strengths and limitations}

Strengths of the present study include its size and the inclusive sample of participants in apparent good health from multiple research centres in three Mediterranean countries, a population that has not been previously studied extensively in terms of associations between social support, Mediterranean diet adherence and physical activity. Correspondingly, to our knowledge, this is one of the first studies to investigate religious services attendance in association with Mediterranean diet and physical activity among Mediterranean populations. Moreover, the present study represents one of the few efforts to investigate the relationship between social support and Mediterranean diet exclusively, as one of the well-established healthy dietary patterns.

The present study is also subject to certain limitations that should be considered. In cross-sectional studies, causal relationships cannot be established between physical activity and social support. Thus, it is not possible to rule out the presence of reverse causality in the results found, that is, people who received more social support are those who were already active. The possibility that this relationship is bidirectional must also be considered, that is, that inactive people who receive social support also become more active or maintain their physical activity levels ${ }^{(41)}$. Moreover, dietary data on Mediterranean diet are based on self-reports, which on top of the cross-sectional study design may limit the relevance of the conclusions. Another possible limitation is that the content validity of some questionnaire items might have been reduced due to the translation of items into Italian, Spanish and Greek. However, all questionnaires were translated from English to all study languages and were checked by bilingual native speakers to ensure that the items correctly captured each construct. Moreover, another limitation of the present study is related to the secondary analyses. The percentage of missing income responses in social support, Mediterranean diet and physical activity questionnaires may impact the association between social support and Mediterranean diet or physical activity. There is also the potential for recall bias. Furthermore, due to a technical error, data were missing for a number of participants. While the missing sample was of a somewhat younger average age, no statistically significant differences were found between the participants with available social support data and the participants with no available social support data in terms of sex and BMI. Moreover, taking into consideration the fact that the study included population from three Mediterranean countries, the use of information in the non-Mediterranean population may be limited.

Overall, methodological inconsistencies exist within the literature on the associations between social support and behavioural change. Social support has been measured using various tools; however, in many cases, these scales were modified for use, or authors use non-validated, custom scales to measure social support. There is a wide number of measures used to appraise social integration or support in the general population or specific patient groups (e.g. arthritis, cancer, CVD and diabetes $)^{(41)}$. Nonetheless, currently, there is no perfect measure of social support, given the lack of consensus regarding the definition and conceptualisation of social support, as well as the relative gap of strong psychometric evidence in the literature for many of the available measures ${ }^{(45)}$. This is problematic because this lack of consistency could lead to imprecise measurement, which has been previously recognised as a challenge ${ }^{(40)}$.

\section{Implications for future research and practice}

Further research is needed to investigate the effects of social support on physical activity and Mediterranean diet adherence including valid measures of social support and its individual components and detailed reporting of potential effect modifiers such as conviviality. Future research should also include the assessment of interventions targeting social support and their impact on the adoption of a healthier lifestyle. Furthermore, while the present study found no association between religious service attendance and Mediterranean diet adherence or physical activity, different religious beliefs and practices may have a different impact on health-related behaviours; the identification of specific factors contributing to the effect of religious participation on health behaviours requires further investigation. Finally, the emergence of digital 
social networking is quickly altering traditional social contacts. Further research is needed to investigate the potential of digital social networking in altering the effect of social support on health behaviours.

Nowadays, the promotion of healthy diet, healthy weight control and physical activity maintenance are considered key parts in forming a sustainable public health policy toward better population health and the prevention of diseases such as CVD, type 2 diabetes and some cancers. Recognising potential social support mediators for use in evidence-based interventions is a crucial step in the improvement of the interventions aiming to encourage individuals and families in making dietary and physical activity choices that may meaningfully improve the health of present and future generations.

\section{Conclusions}

Our findings suggest that emotional support availability and number of close friends may be positively associated with Mediterranean diet adherence. However, traditional social contacts may not be strongly associated neither with physical activity, nor with healthy diet adherence. The potential of digital technologies in altering the effect of social support on health behaviours needs further investigation. To that end, the further conceptualisation of social support and development of valid and up to date social support measures are needed.

\section{Supplementary material}

The supplementary material for this article can be found at https://doi.org/10.1017/jns.2020.46.

\section{Acknowledgements}

This work was supported by the European Union's Seventh Framework Program (FP7/2007-2013) under grant agreement $\mathrm{n}^{\circ}$ 602386. The funders had no role in study design, data collection and analysis, decision to publish, or preparation of the manuscript.

Study concept and design: M. L. B., R. S., L. S. M., E. E. N., A. T.; Acquisition, analysis, or interpretation of data: all authors; Drafting of the manuscript: all authors; Statistical analysis: E. L., G. M., I. R., E. E. N.; Obtained funding: M. L. B., R. S., L. S. M., E. E. N., A. T.; Administrative, technical, or material support: none; Study supervision: M. L. B., R. S., L. S. M., E. E. N., A. T.

This study was contacted according to the guidelines laid down in the declaration of Helsinki and all procedures involving research study participants were approved by the respective national review boards. Ethical approval for the study was provided by the Ethics Committee of Area Vasta Centro (Florence, Italy); Ethics Committee of ASL (Lecce, Salento, Italy); Ethics Committee of ASL (Brindisi, Italy); Comisión de Bioética de la Universidad de Barcelona (Barcelona, Spain) and Greek National Ethical Committee (Greece). Written informed consent was obtained from all subjects/patients.

All authors declare no conflict of interest.

\section{References}

1. Taylor SE (2012) Social support: a review. In Oxford Handbooks of Health Psychology. Oxford, UK: Oxford University Press.

2. Friedman HS (Ed.) (2014) The Oxford Handbook of Health Psychology. Oxford, UK: Oxford University Press; 915 pp.

3. Langford CPH, Bowsher J, Maloney JP, et al. (1997) Social support: a conceptual analysis. J Adv Nurs 25, 95-100.

4. Cohen JFW, Richardson SA, Cluggish SA, et al. (2015) Effects of choice architecture and chef-enhanced meals on the selection and consumption of healthier school foods a randomized clinical trial. JAMA Pediatr 169, 431-437.

5. Bandura A (1986) Social Foundations of Thought and Action: A Social Cognitive Theory. Englewood Cliffs, NJ: Prentice-Hall.

6. Ajzen I (1991) The theory of planned behavior. Organ Behav Hum Decis Process 50, 179-211.

7. Mcleroy KR, Bibeau D, Steckler A, et al. (1988) An ecological perspective on health promotion programs. Health Educ Behav $15,351-377$.

8. Schwarzer R (2008) Modeling health behavior change: how to predict and modify the adoption and maintenance of health behaviors. Appl Psychol 57, 1-29.

9. Pieroth R, Rigassio Radler D, Guenther PM, et al. (2017) The relationship between social support and diet quality in middle-aged and older adults in the United States. J Acad Nutr Diet 117, $1272-1278$.

10. Conklin AI, Forouhi NG, Surtees P, et al. (2014) Social relationships and healthful dietary behaviour: evidence from over-50s in the EPIC cohort, UK. Soc Sci Med 100, 167-175.

11. Ferranti EP, Dunbar SB, Higgins M, et al. (2013) Psychosocial factors associated with diet quality in a working adult population. Res Nurs Health 36, 242-256.

12. Carron AV, Hausenblas HA \& Mack D (1996) Social influence and exercise: a meta-analysis. J Sport Exerc Psychol 18, 1-16.

13. Uchino BN (2009) Understanding the links between social support and physical health: a life-span perspective with emphasis on the separability of perceived and received support. Perspect Psychol S Si 4, 236-255.

14. Warner LM, Schüz B, Wurm S, et al. (2010) Giving and taking Differential effects of providing, receiving and anticipating emotional support on quality of life in adults with multiple illnesses. J Health Psychol 15, 660-670.

15. Martinez-Gonzalez MA \& Bes-Rastrollo M (2014) Dietary patterns, Mediterranean diet, and cardiovascular disease. Curr Opin Lipidol 25, $20-26$.

16. U.S. Department of Health and Human Services and U.S. Department of Agriculture. (2015) Dietary Guidelines for Americans 2015-2020, 8th Ed. Available at http://health.gov/dietaryguidelines/2015/guidelines/.

17. Renzella J, Townsend N, Jewell J, et al. (2018) What national and subnational interventions and policies based on Mediterranean and Nordic diets are recommended or implemented in the WHO European Region, and is there evidence of effectiveness in reducing noncommunicable diseases? WHO Reg Off Eur Health Evi 58, 1-74.

18. WHO (2015) Global Recommendations on Physical Activity for Health. World Health Organization.

19. WHO (2003) World Health Organization: Process for a Global Strategy on Diet, Physical Activity and Health. World Health Organization.

20. WHO (2015) Fiscal Policies for Diet and Prevention of Noncommunicable Diseases.

21. Maher CA, Lewis LK, Ferrar K, et al. (2014) Are health behavior change interventions that use online social networks effective? A systematic review. J Med Internet Res.

22. Schwarzer R, Fleig L, Warner LM, et al. (2016) Who benefits from a dietary online intervention? Evidence from Italy, Spain and Greece. Public Health Nutr 20, 938-947.

23. Berkman LF, Seeman TE, Albert M, et al. (1993) High, usual and impaired functioning in community-dwelling older men and 
women: findings from the MacArthur Foundation Research Network on successful aging. J Clin Epidemiol 46, 1129-1140.

24. Berkman LF \& Syme SL (1979) Social networks, host resistance, and mortality: a nine-year follow-up study of Alameda County residents. Am J Epidemiol 109, 186-204.

25. NHANES 2005-2006: Social Support Data Documentation, Codebook, and Frequencies. https://wwwn.cdc.gov/Nchs/ Nhanes/2005-2006/SSQ_D.htm (accessed September 2020).

26. Ahmad S, Harris T, Limb E, et al. (2015) Evaluation of reliability and validity of the General Practice Physical Activity Questionnaire (GPPAQ) in 60-74 year old primary care patients. BMC Fam Pract 16, 113.

27. Sarason IG, Sarason BR, Shearin EN, et al. (1987) A brief measure of social support: practical and theoretical implications. J Soc Pers Relat 4, 497-510.

28. Martínez-González MA, García-Arellano A, Toledo E, et al. (2012) A 14-item Mediterranean diet assessment tool and obesity indexes among high-risk subjects: the PREDIMED trial. PLoS ONE 7, e43134.

29. Bamia C, Martimianaki G, Kritikou M, et al. (2017) Indexes for assessing adherence to a Mediterranean diet from data measured through brief questionnaires: issues raised from the analysis of a Greek population study. Curr Dev Nutr 1, e000075.

30. Schröder H, Fitó M, Estruch R, et al. (2011) A short screener is valid for assessing Mediterranean diet adherence among older Spanish men and women. J Nutr 141, 1140-1145.

31. McKenzie LE, Polur RN, Wesley C, et al. (2013) Social contacts and depression in middle and advanced adulthood: findings from a US national survey, 2005-2008. Int J Soc Psychiatry 59, 627-635.

32. World Health Organization (2020) Body Mass index - BMI. World Health Organization.

33. Bauman AE, Reis RS, Sallis JF, et al. (2012) Correlates of physical activity: why are some people physically active and others not? Lancet, 258-271.
34. Smith G L, Banting L, Eime R, et al. (2017) The association between social support and physical activity in older adults: a systematic review. Int J Behav Nutr Phys Act 14, 56.

35. Trost SG, Owen N, Bauman AE, et al. (2002) Correlates of adults' participation in physical activity: review and update. Med Sci Sports Exerc 1996-2001.

36. Koeneman MA, Verheijden MW, Chinapaw MJM, et al. (2011) Determinants of physical activity and exercise in healthy older adults: a systematic review. Int J Behav Nutr Phys Act 8, 142.

37. Rhodes RE \& Quinlan A (2015) Predictors of physical activity change among adults using observational designs. Sports Med 45, 423-441.

38. Amireault S, Godin G \& Vézina-Im LA (2013) Determinants of physical activity maintenance: a systematic review and meta-analyses. Health Psychol Rev 7, 55-91.

39. Prince SA, Reed JL, Martinello N, et al. (2016) Why are adult women physically active? A systematic review of prospective cohort studies to identify intrapersonal, social environmental and physical environmental determinants. Obes Rev 919-944.

40. Laird Y, Fawkner S, Kelly P, et al. (2016) The role of social support on physical activity behaviour in adolescent girls: a systematic review and meta-analysis. Int J Behav Nutr Phys Act 13, 79.

41. Heitzmann CA \& Kaplan RM (1988) Assessment of methods for measuring social support. Heal Psychol 7, 75-109.

42. Shaikh AR, Yaroch AL, Nebeling L, et al. (2008) Psychosocial predictors of fruit and vegetable consumption in adults: a review of the literature. Am J Prev Med 34, 535-543.

43. Lara J, Evans EH, O’Brien N, et al. (2014) Association of behaviour change techniques with effectiveness of dietary interventions among adults of retirement age: a systematic review and meta-analysis of randomised controlled trials. BMC Med 12, 177.

44. Bach-Faig A, Berry EM, Lairon D, et al. (2011) Mediterranean diet pyramid today. Science and cultural updates. Public Health Nutr 14, 2274-2284.

45. López ML \& Cooper L (2011) Social Support Measures Review. Los Angeles, CA: First 5 LA. 